\title{
Gender Differences in Intimate Partner Violence Victimization, Help- Seeking, And Outcomes Among College Students
}

\author{
Hyunkag Cho \\ Jisuk Seon \\ Ga-Young Choi \\ Soonok An \\ Ilan Kwon \\ Yoon Joon Choi \\ Seunghye Hong \\ Jungeun Olivia Lee \\ Esther Son \\ Sung Hyun Yun
}

\begin{abstract}
Many college students experience intimate partner violence (IPV). Although receiving help from formal and informal sources may ameliorate possible negative impacts of IPV victimization, the outcomes of help-seeking are not always positive. This study used survey data collected at six universities across the United States (U.S.) to examine gender differences in IPV, help-seeking, and its outcomes (n=3,070). Major variables included $I P V$ victimization, IPV consequences, help-seeking, and outcomes. Descriptive and bivariate analyses revealed higher rates of victimization among females as well as poorer health status, higher levels of depression, and more daily routine problems. Females also used more formal help, and reported it as being useful more often than males. Inversely, more males than females reported that informal supports were helpful. Recommendations include social workers providing tailored services both for male and female survivors, service providers developing educational programs that target informal help sources, and social work education providing relevant trainings.
\end{abstract}

Keywords: Intimate partner violence; gender; help-seeking; college

Many college students encounter intimate partner violence (IPV) and suffer a wide range of behavioral, mental, and physical health outcomes. Importantly, IPV victimization during young adulthood, including the college years, is likely to lead to continuous victimization in adulthood, possibly throughout a lifetime (Greenman \& Matsuda, 2016; Smith et al., 2003). It is critical for IPV survivors to seek help to reduce both the negative consequences of IPV and the likelihood of future victimization. Indeed, after victimization, most survivors seek help from a variety of sources, both formal (e.g., police, health clinics) and informal, such as family and friends (Cho \& Huang, 2017). However, the outcomes of

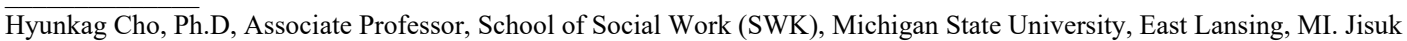
Seon, PhD, Postdoc Researcher, School of SWK, Washington University, St. Louis, MO. Ga-Young Choi, PhD, Associate Professor, School of SWK, California State University, Los Angeles, CA. Soonok An, PhD, Assistant Professor, Department of SWK and Sociology, North Carolina A\&T State University, Greensboro, NC. Ilan Kwon, Ph.D, Adjunct Lecturer, School of SWK, Michigan State University, East Lansing, MI. Yoon Joon Choi, PhD, Associate Professor, School of SWK, University of Georgia, Athens, GA. Seunghye Hong, PhD, Associate Professor, Myron B. Thompson School of SWK, University of Hawai'i at Mānoa, Honolulu, HI. Jungeun Olivia Lee, PhD, Assistant Professor, Suzanne Dworak-Peck School of SWK, University of Southern California, Los Angeles, CA. Esther Son, PhD, Assistant Professor, School of Health Sciences, Department of SWK, College of Staten Island, The City University of New York, Staten Island, NY. Sung Hyun Yun, PhD, Associate Professor, School of SWK, University of Windsor, Windsor, Ontario, Canada. 
help-seeking are not always positive, and are sometimes even detrimental to the survivors' well-being, which may lead victims to avoid it in the future (Laing, 2017; Rich \& Seffrin, 2013). There seem to be gender differences not only in IPV victimization, but in helpseeking as well. For instance, females experienced more physical but less psychological violence than males (Breiding et al., 2014); and males sought more informal but less formal help than females (Cho et al., in press). However, study results on these aspects of IPV are somewhat limited, due to small sample sizes, inclusion of only certain types of IPV (e.g., physical or sexual violence), exclusion of help-seeking outcome measures, and a lack of gender perspective. This study attempts to fill this gap by using a large, relatively recent dataset to examine gender differences in IPV victimization, help-seeking, and its outcomes.

\section{Gender Differences in IPV Prevalence and Consequences}

IPV involves physical, sexual, and psychological violence against an individual by current or former intimate partners, such as a boy/girlfriend, dating partner, or spouse (Campbell, 2016). Physical violence is the intentional use of physical force with the potential for causing death, disability, injury, or harm; sexual violence is a sexual act that is committed or attempted by another person without freely given consent of the victim or against someone who is unable to consent or refuse; psychological violence is the use of verbal and non-verbal communication with the intent to harm another person mentally or emotionally, and/or exert control over another person, which can take the form of threats that is the use of words, gestures, or weapons to communicate the intent to cause death, disability, injury, or physical harm (Breiding et al., 2015). IPV also takes the form of technological violence that consists of acts through technology that are intended to cause harm to intimate partners as well as control partners' behavior (Watkins et al., 2018).

At least one in five college students has endured IPV (Wasserman, 2003). IPV prevalence varies when examining specific types of violence. Approximately $22 \%$ of college students suffered physical violence, while 52\% reported psychological victimization in the past year (Gover et al., 2008). Another study reported that about $30 \%$ of female college students had experienced sexual or physical violence, and that $83 \%$ had been victimized by psychological violence during their college years (Fass et al., 2008). A review of the results from nine studies found that IPV prevalence rates among college students ranged from $1 \%$ to $31 \%$ for physical violence, from $10 \%$ to $77 \%$ for psychological violence, and from $10 \%$ to $36 \%$ for sexual violence (Scherer et al., 2016). Overall, psychological violence seems to be the type of IPV college students face most frequently, followed by physical and/or sexual violence (Cho \& Huang, 2017; Fass et al., 2008; Gover et al., 2008).

There are gender differences in IPV experiences, but with variations across studies (Dardis et al., 2017; Saewyc et al., 2009). According to a study with 254 college students, while females and males reported similar rates of psychological (female, $83 \%$ and males, $87 \%$ ) and sexual (females, $30 \%$ and males, $27 \%$ ) violence victimization, male students reported more physical violence (42\%) than females (32\%; Fass et al., 2008). Another study found no gender differences in physical victimization, but more psychological victimization for females (57\%) than males (50\%; Gover et al., 2008). A 2017 study of 704 
college students found no statistically significant difference between males and females in physical, sexual, or psychological victimization (Dardis et al., 2017).

Gender differences in IPV prevalence appear to be far from consistent. Different methodological approaches in previous studies may account for the gender differences in IPV prevalence among college students. For example, some studies included many types of IPV, reporting higher overall rates of IPV (Amar \& Gennaro, 2005) than other studies that measured IPV using one or two violence types, such as physical, psychological, or sexual (Gover et al., 2008; Saewyc et al., 2009). Some studies reported higher rates of IPV by asking about lifetime prevalence (Garcia-Moreno et al., 2006; Kilpatrick et al., 2000), compared to those asking about IPV experienced only in the past six or 12 months (Daley \& Noland, 2001). Similarly, studies measuring IPV experiences with all partners in current and prior relationships tend to report higher IPV rates (Gover et al., 2008). Thus, variations in IPV estimates among college students reflect the use of different measures (Hamby, 2016; Harned \& Vict, 2001; Woodin et al., 2013).

IPV leads to acute and chronic physical and mental health problems, including injury, depression, anxiety, low self-esteem, suicide attempts, substance abuse, and sexually transmitted diseases (Breiding et al., 2014; Jina \& Thomas, 2013; Lutwak, 2018). Sexual assault victimization, for example, was associated with female college students' poor selfesteem, depression, anxiety, suicidal ideation, and substance abuse (Banyard \& Cross, 2008; Neville et al., 2004; Santaularia et al., 2014). A nationally representative study in Spain of 10,171 women over the age of 16 found that physical and sexual violence predicted poor health symptoms such as anxiety, sadness, wanting to cry, mood swings, and insomnia (Domenech del Rio \& Sirvent Garcia del Valle, 2017). Technological violence, such as cyberbullying and cyber dating abuse, among college students appeared to predict low self-esteem and heightened emotional distress (Hancock et al., 2017).

Research on IPV consequences indicates there are gender differences. For example, Harned and Vict (2001) found that both female and male student survivors of physical and psychological IPV showed similar levels of depressive and anxiety symptoms at lower levels of IPV aggression, while at higher levels of aggression female student survivors showed more depressive and anxious symptoms than males. In a sample of 502 Italian university students, Romito and Grassi (2007) found that female student survivors who experienced high levels of IPV reported increased depression and a greater frequency of panic than those who experienced low or no IPV. While both men and women reported depressive symptoms after IPV (Porcerelli et al., 2003), female survivors tended to experience more depression and anxiety than males (Ehrensaft et al., 2006; Fergusson et al., 2005; Romito \& Grassi, 2007). Female survivors of severe violence were 3 times more likely to be clinically diagnosed with depression than male counterparts (Kars \& O'Leary, 2010). Male survivors seemed to suffer primarily from disruptive behavior disorder and substance use, while the list of mental health issues for female survivors was much larger, including suicide attempts and internalizing disorders (Afifi et al., 2009; Coker et al., 2002; Romito \& Grassi, 2007). A study on post-traumatic stress disorder (PTSD) showed that women were more likely to report PTSD than men, with one explanation being that women more often felt higher levels of fear of their partners (Caldwell et al., 2012). Female survivors, compared to their male counterparts, were more likely to get injured during an 
incident of IPV (Breiding et al., 2014; Straus \& Gozjolko, 2014). Moreover, women tend to sustain the negative effect of physical injuries longer than men (Hamberger \& Larsen, 2015). Intimate partner homicide disproportionately affected women; $54 \%$ of female homicides are committed by a present or former intimate partner, compared with up to $30 \%$ for male homicides (Guth \& Pachter, 2000). Velopuloset al. (2019) reported even higher homicide rates for women than men ( $79 \%$ vs. $21 \%$ ). Overall, female survivors seem to suffer more severe consequences from IPV victimization compared to males.

\section{Gender Differences in Survivors' Help-Seeking}

IPV survivors may reduce both the negative consequences of IPV and the likelihood of future victimization by seeking help. The majority of IPV survivors who seek help handle the negative health consequences through formal sources such as mental health professionals or domestic violence service agencies, and/or through informal sources such as family members or friends (Ansara \& Hindin, 2010). Studies in North America have consistently found that IPV survivors are more likely to seek informal than formal help (Cho \& Huang, 2017; Coker et al., 2000; Edwards et al., 2011). In a recent study of IPV among college students, for example, approximately $89 \%$ of the students sought informal help and only $23 \%$ of the sample sought formal help (Cho \& Huang, 2017). In a populationbased sample, Ansara and Hindin (2010) reported a similar pattern: approximately $81 \%$ of women and $57 \%$ of men who had experienced physical or sexual IPV sought help from an informal source, whereas about $64 \%$ of women and $32 \%$ of men sought formal help. The most commonly reported informal sources of help include family members and friends (Ansara \& Hindin, 2010; Cho \& Huang, 2017; Edwards et al., 2011), and oft-reported formal sources of help are health professionals and counselors (Ansara \& Hindin, 2010).

Understanding differences and similarities in help-seeking behaviors of men and women victimized by IPV is somewhat difficult using the existing literature, as most studies focus on IPV suffered by either men or women, and they use different measures of IPV or of help-seeking. Nevertheless, recent IPV research reflects that higher rates of women than men seek help for psychological (Fortin et al., 2012), physical, or sexual IPV (Ansara \& Hindin, 2010; Coker et al., 2000). In one study by Edwards et al. (2011), female college-age survivors preferred disclosing their IPV experiences to female friends (73\%), followed by male friends $(25 \%)$, sisters $(25 \%)$, or mothers $(23 \%)$. Only $5 \%$ of the female students who disclosed IPV to a helping source reported disclosing it to a counselor, and none reported seeking help from a medical doctor, law enforcement, or a priest or minister (Edwards et al., 2011). Similarly, in another study, male survivors of IPV reported the use of informal help more than formal help. Approximately $77 \%$ of males revealed that they sought informal help from male friends or a neighbor, which are the most frequently reported sources of help (Douglas \& Hines, 2011). In the same study, almost $44 \%$ of men sought help from a domestic violence agency, and close to a quarter of the men (23.4\%) used a domestic violence hotline, although only $18 \%$ sought help from medical professionals (Douglas \& Hines, 2011). However, Ansara and Hindin (2010) reported that very few men who experienced physical or sexual IPV used male-focused survivor services such as a men's support group (3.7\%) and crisis hotlines (3.8\%). 
One of the limitations of IPV research is the underrepresentation of sexual minorities (Calton et al., 2016). Most studies have examined only heterosexual intimate relationships (e.g., Ansara \& Hindin, 2010; Douglas \& Hines, 2011) or have not reported study participants' sexual orientation (e.g., Edwards et al., 2011). As a result, gender differences in help-seeking behaviors of IPV survivors in non-heterosexual relationships are relatively unknown. Nonetheless, the few existing studies suggest that IPV survivors in nonheterosexual relationships are less likely to seek help due to the barriers that heterosexual survivors do not encounter. For example, the survivors who are closeted could be threatened by their partners to disclose their sexual orientation to their families, friends, and/or employment if they attempt to seek help (Calton et al., 2016). The abusers may use homophobia as a tactic to stop the survivors from seeking help, telling them that they are not welcomed or believed by service providers (Calton et al., 2016; Duke \& Davidson, 2009). Service providers' lack of understanding of the needs of non-heterosexual IPV survivors may create unique challenges for the survivors. For instance, Ard and Makadon (2011) pointed out a lack of sensitivity among medical service providers when assessing non-heterosexual patients' IPV experiences. Providers tend to refer to survivors' partners as husbands (wives) if the survivors are women (men), assuming heterosexual relationships for all patients. Moreover, not all states provide legal protection (such as protective orders) for non-heterosexual IPV survivors under domestic violence statutes (Calton et al., 2016; Duke \& Davidson, 2009). Homophobic attitudes of law enforcement and IPV service providers, and the operation of domestic violence shelters centered around heterosexual female IPV survivors may also act as barriers for non-heterosexual IPV survivors seeking help (Calton et al., 2016).

\section{Gender Differences in the Outcomes of Help-Seeking}

Existing studies have measured the outcomes of help-seeking behaviors through the lens of their perceived helpfulness or their impact on mental health/well-being including psychological distress, depression, posttraumatic stress disorder, substance abuse, or selfesteem (Douglas \& Hines, 2011; Fortin et al., 2012; Sylaska \& Edwards, 2014). Coker and colleagues (2000) found that a large portion of the survivors of physical IPV reported that formal sources were helpful. More specifically $85 \%$ of female survivors reported doctors/nurses to be helpful, $80 \%$ found mental health counselors/therapists to be of value, and $67 \%$ reported domestic violence shelter staff were helpful. While the majority of male survivors in their study also reported these formal sources as being beneficial, the sample size of men was too small to make a meaningful comparison. Multiple studies show that survivors perceive friends to be the most useful and supportive informal source of help (Sylaska \& Edwards, 2014). At the same time, friends have also often been reported as the least helpful source of help (Edwards et al., 2011). It appears that survivors perceive their informal sources as helpful when survivors receive emotional support or tangible support (e.g., being offered a place to stay), or obtain practical advice (e.g., being encouraged to seek legal or counseling support). On the other hand, survivors consider the informal sources as unhelpful when they do not take IPV situations seriously, blame the survivors, or pressure the survivors to take specific actions such as breaking up the relationship (Edwards et al., 2011; Sylaska \& Edwards, 2014). 
Survivor services such as domestic violence agencies, shelters, and crisis hotlines are among the core resources for IPV survivors. However, the literature suggests a notable difference between women and men when it comes to the outcomes of using such services. For example, female rape survivors who had assistance from rape survivor advocates, compared to those who did not work with advocates, reported more positive experiences in accessing legal and medical systems to remedy their IPV-related issues (Campbell, 2006). Moreover, a study that followed female IPV survivors for two years showed that $24 \%$ of women who received help from advocates were free from IPV, compared to only $10 \%$ of women who did not (Sullivan \& Bybee as cited in Bennett et al., 2004). Contrary to such findings, studies that focused on men indicate that men perceived survivor services as unhelpful or less helpful (Douglas \& Hines, 2011; Tsui, 2014). Negative experiences of male survivors' service utilization may result from a lack of services available to males (Tsui, 2014) and from being rejected by service providers claiming that they only help women (Douglas \& Hines, 2011).

In sum, the current literature suggests there are gender differences in IPV victimization among college students, their help-seeking, and the outcomes. However, previous study results are not consistent and are somewhat limited in their methodology. Many studies relied on small samples; included only certain types of IPV, thereby not representing the whole scope of IPV; did not measure help-seeking outcomes; and/or included only one gender, and thus were not able to examine gender differences. This study strengthens the current literature by (a) collecting data from a large sample of college students; (b) including a variety of IPV types; (c) measuring perceptions of the helpfulness of helpseeking after IPV; (d) examining gender differences in all of these aspects of IPV; and (e) including non-heterosexual IPV survivors. The current study aimed to answer four research questions: (a) What are the differences in characteristics between IPV survivors and those not experiencing IPV?, (b) Are there gender differences among IPV survivors by IPV types experienced, health, and help-seeking behaviors?, (c) Are there gender differences in helpseeking outcomes among IPV survivors?, and (d) Are there gender differences among IPV survivors who did not seek any help in reasons for not seeking help?

\section{Methods}

\section{Study Sample}

The data are from cross-sectional online surveys conducted from 2016 through 2017. Undergraduate and graduate students at six universities across the U.S. were recruited to participate, including east-coast, west-coast, southern, and Midwest universities. Each university recruited students independently, using convenience sampling methods, such as student mailing lists and student organizations. All survey participants, except those at two universities where incentives were not allowed, were given the option of opting into a raffle for gift cards. Each university implemented the surveys independently. The current study sample consisted of 3,070 undergraduate students who had been in romantic relationships for at least a month, which was likely to indicate that they have had intimate partners. This study was approved by the Institutional Review Boards at each of the participating universities. 


\section{Measures}

\section{IPV Victimization}

IPV victimization was measured with five different types: threats, physical, sexual, technological, and psychological victimization. Questions on threats, and on physical and sexual violence were adopted from the Partner Victimization Scale (Hamby, 2013); questions on technological violence were from Southworth, Finn, Dawson, Fraser, and Tucker (2007); and psychological violence questions were from Ansara and Hindin (2010). Participants were asked whether they had ever experienced such violence by their current and/or previous romantic partners, including boyfriends, girlfriends, husbands, or wives. There were a total of 12 items used (Cronbach's alpha=0.78): one for threats (e.g., "Not including horseplay or joking around, my partner threatened to hurt me and I thought I might really get hurt"), three for physical victimization (e.g., "Not including horseplay or joking around, my partner pushed, grabbed, or shook me"), one for sexual victimization (e.g., "My partner made me do sexual things when I did not want to"), two for technological victimization (e.g., "My partner sent emails or text messages to threaten, insult, or harass me"), and five for psychological victimization (e.g., "My partner tried to limit my contact with family or friends"). Each item was rated based on a 4-point Likert scale ranging from 0 (Never) to 4 (Four times or more). The sum of each of the five IPV types was obtained and dichotomized: $0=$ "No victimization by a certain type of IPV", and $1=$ "at least one victimization by that type". Another variable was created to represent overall IPV victimization by adding all of the items in the scale together; it was also dichotomized: $0=$ "No IPV victimization" and 1="at least one IPV victimization".

\section{IPV Consequences}

IPV consequences were measured with three questions adopted from the Partner Victimization Scale (Hamby, 2013). Those who had experienced IPV victimization at least once were asked: Whether they had physical injuries (e.g., "Were you physically hurt when this happened?") or daily routine problems (e.g., "Did you miss any days of school, work, or your normal routine because of what happened?"), and how much they were afraid (e.g., "Thinking back to when it happened, how afraid did you feel?") at the most recent IPV incident. While physical injuries and daily routine problems had two response options, "Yes" or "No", feeling afraid had three response options, "Not at all", "A little", and "Very".

\section{Help-Seeking and Outcomes}

To those who had experienced at least one type of IPV victimization, their help-seeking behaviors were assessed using a single item-"Have you talked about any of these incidents with any agencies or persons?"-with "Yes" or "No" response options. Participants who answered "Yes" to this question were considered as having sought any help after IPV victimization. Those who had sought help were then asked to identify which types of help they used from among 13 help sources. Seven help sources (e.g., medical services, shelter, and police) were considered formal help; six sources (e.g., family, friends, and coworkers) were considered informal help. With "Yes" or "No" response options, participants were asked to indicate as many help sources as they used. Outcomes of help- 
seeking were asked of those who reported having used at least one help source ("Do you think the assistance you received was helpful?"), with "Yes" or "No" response options. If the participants did not use any help source, they were asked about the reasons for not seeking help. Twelve reasons were provided (e.g., private or personal matter, no insurance, and afraid of reprisal by partner); the list was informed by the National Crime Victimization Survey (Langton et al., 2012). Participants were able to check multiple reasons.

\section{Physical and Behavioral Health}

Self-perceived health status was measured with two questions: "How would you rate your overall physical health?" and "How would you rate your overall mental health?" Respondents were offered five response options - "Excellent", "Very good", "Good", "Fair", and "Poor"-which were dichotomized for the analysis: "Good"(combining Excellent, Very good, and Good) and "Not good" (combining Fair and Poor).

Depression was measured by the Center for Epidemiologic Studies Depression Scale (Radloff, 1977), which consisted of 20 items assessing how often during the previous week the participants had experienced symptoms regarding restless sleep, poor appetite, and feeling lonely. The 4-point Likert scale response options ranged from 0 (rarely or none of the time [less than 1 day]) to 3 (most or all of the time [5-7 days]). The sum of each item was calculated and treated as a continuous variable, ranging from 0 (no depressive symptoms) to 60 (the highest depression). The reliability of this scale was 0.92 .

Body mass index (BMI) was measured to see if IPV was associated with physical health and calculated using participants' reported weight in pounds and height in inches. Specifically, it was calculated by dividing weight by height squared, and multiplied by a conversion factor of 703 (Centers for Disease Control and Prevention [CDC], 2014). Based on commonly accepted BMI classifications, such as Underweight - under 18.5, Normal18.5 to 25 , Overweight - 25 to 30, and Obese - over 30 (CDC, 2014), two BMI categories were created: Under or normal weight (under 18.5-25) and Overweight (25 to over 30).

Alcohol use was measured by asking "In the past 12 months, how often did you usually have at least one drink? It means either a glass of wine, a can or bottle of beer, or a shot or jigger of liquor (i.e., 1 1/2 fluid ounces) either alone or in a mixed drink," with six response options ranging from 0 (Did not drink) to 5 (Nearly every day). Responses were reduced to three categories: Non-Drinker (Did not drink), Casual drinker (Less than once a month to one-two days per week), and Heavy drinker (three-four days per week and nearly every day).

Drug use was measured by asking "In the past 12 months, how often did you use marijuana, hashish, cocaine, heroin, LSD, or prescription drugs for any reason other than a health professional said you should use them?" with the same response options as were offered regarding alcohol use. Responses were reduced to three categories: Non-User (Did not use), Casual user (Less than once a month to one-two days per week), and Heavy user (three-four days per week and nearly every day). 


\section{Demographics Characteristics}

Various demographic characteristics were included to describe the sample. Age was asked in years and treated as a continuous variable. Gender was assessed as "Female," "Male," or "Other." Participants who identified themselves as "Other (e.g., transgender)" were excluded in the analyses due to their small number. Sexual orientation was subsequently asked with six response options ("Heterosexual or Straight", "Gay or Lesbian", "Bisexual", "Transgender", "Don't know", "Other") and dichotomized for this study as Heterosexual (Heterosexual or Straight) and Non-Heterosexual (all other response options). Race was asked with "Asian, Pacific Islander," "Black, African American (nonHispanic)," "Spanish, Hispanic, Latino," "White, Caucasian, European (non-Hispanic)," "American Indian, Native American, Native Canadian, First Nations," Multi-ethnic," and "Other." School years were measured with 5 categories: "Freshman," "Sophomore," "Junior," "Senior," and "Other." Additional demographic information was collected from participants, including questions about religion, financial security, residence, internationality, IPV training, and neighborhood environments. Religion was measured with seven categories (e.g., No religion, Christianity, Hindu) and reduced for this study to a dichotomous variable: Religious and Non-Religious. Financial security was measured with six categories, ranging from "Very secure" to "Very insecure," and dichotomized into Secure and Insecure. Residence was measured by asking if the respondent lived in a college dorm: "Yes" or "No". Internationality was measured by asking if the respondent was an international student or born abroad: "Yes" or "No". IPV training was measured by asking if the respondent had taken any class and/or training that discussed relationship violence: "Yes" or "No". Current and childhood neighborhood environments were measured by asking "How true is each of the following statements about your neighborhood when you were a child?" and "How true is each of the following statements about your neighborhood where you live most of the time?" using the Neighborhood Cohesion and Safety Scale (Alegria et al., 2004). This scale consists of seven items to assess participants' perceptions of neighborhood cohesion (e.g., "People in my neighborhood could be trusted") and safety (e.g., "I felt safe being out alone or with my family in this neighborhood during the night") based on a 4-point Likert scale, ranging from 0 (Not at all true) to 3 (Very true). The sum of each item was calculated and treated as a continuous variable, ranging from 0 to 21 . Higher points indicate higher levels of perceived neighborhood cohesion and safety. The reliability of this scale was 0.83 (current neighborhood) and 0.87 (childhood neighborhood), respectively.

\section{Analysis}

We ran multiple descriptive and bivariate analyses. First, the sample was split into two groups: IPV (those who reported any type of IPV victimization, $n=1,901$ ) and non-IPV (those who did not report any IPV victimization, $n=1,169$ ). Separate bivariate analyses were conducted with each of the two groups to examine whether there were gender differences among all demographic variables, and in the physical and behavioral health variables (research question 1). We then looked to see if there were differences between groups. Next, with the IPV group $(n=1,901)$, we analyzed IPV types, consequences, and help-seeking by gender (research question 2). Third, for those who sought any type of help 
( $n=519)$, help-seeking outcomes were analyzed by gender (research question 3 ). Finally, for those who did not seek any help $(n=1,116)$, each of twelve reasons for not seeking help was analyzed by gender (research question 4). In all of the analyses, frequencies and percentages were reported for categorical variables; means and standard deviations were reported for continuous variables. Pearson's chi-square tests or independent $t$-tests were conducted for all bivariate analyses to examine gender differences in IPV experiences. Effect sizes were reported by Cramer's $V$ for the chi-square tests and Cohen's $d$ for the ttests. In addition, we conducted a series of post hoc analyses for pairwise comparison using the Bonferroni adjusted alpha levels per test to protect from yielding inflated Type I errors (MacDonald \& Gardner, 2000). SPSS v. 22 was used for all analyses.

\section{Results}

Table 1 shows the sample characteristics for those who experienced IPV victimization and those who did not. Nearly $62 \%$ of students experienced at least one type of IPV victimization. Regardless of gender, the respondents reporting at least one type of IPV were engaged in risky substance use, and reported health concerns, more than those reporting no IPV victimization. In addition, many gender differences were found among IPV survivors. To be specific, compared to male students with IPV victimization, female counterparts reported older age $(t(800)=0.75, p<0.01, d=.58)$, more Hispanic origin $\left(\chi^{2}(4)=8.33, p<\right.$ $0.05, V=.01)$, less safe neighborhood in childhood $(t(500)=-2.05, p<0.05, d=.06)$, poorer physical and mental health status $\left(\chi^{2}(1)=30.64, p<0.001, V=.20 ; \chi^{2}(1)=7.71, p<0.01\right.$, $V=.13$, respectively), and higher depression scores $(t(661)=5.40, p<0.01, d=.41)$. Post hoc comparisons using the adjusted Bonferroni correction showed significant gender differences in behavioral health. Specifically, more male students reported mental health as "Good" $(0.05 / 4=.0125)$ while more female students were non-drug users $(0.05 / 6=.0083)$. However, the other variables showed no gender differences.

Except for psychological violence, female students experienced significantly more IPV victimization than male students (Table 2). Of the five IPV types, psychological violence was the most prevalent for both male and female students, followed by physical violence. Sexual violence showed the biggest gender difference, with $47.3 \%$ of female students and $14.3 \%$ of male students victimized $\left(\chi^{2}(1)=147.17, p<.001, V=.32\right)$. Each post hoc comparison using the adjusted Bonferroni correction $(0.05 / 4=.0125)$ for the five types of violence indicated that all pairwise gender differences, except for psychological violence, were significant.

Among those who experienced any type of IPV victimization, female students suffered from all three types of consequences more than their male counterparts being physically hurt, feeling afraid when victimized, and having problems with daily routines afterwards. The biggest gender difference was found in feeling afraid; $66.5 \%$ of female students were a little or very afraid, while $75.8 \%$ of males did not feel afraid at all $\left(\chi^{2}(1)=209.61, p<.001\right.$, $V=.17)$. However, each post hoc comparison using the adjusted Bonferroni correction for physical injuries $(0.05 / 4=.0125)$, daily routine problems $(0.05 / 4=.0125)$, and feeling afraid $(0.05 / 6=.0083)$ showed that none of pairwise comparisons was significant. 
Table 1. Gender Differences in IPV Victimization, Demographics, and Physical and Behavioral Health $(n=3,070)$

\begin{tabular}{|c|c|c|c|c|c|c|}
\hline \multirow[b]{2}{*}{ Demographics } & \multicolumn{3}{|c|}{$\begin{array}{c}\text { IPV Victimization }(n=1,901) \\
\mathrm{n}(\%) / M(S D)^{\mathrm{a}} \\
\end{array}$} & \multicolumn{3}{|c|}{$\begin{array}{c}\text { No IPV Victimization }(n=1,169) \\
\mathrm{n}(\%) / M(S D)^{\mathrm{a}}\end{array}$} \\
\hline & Female & Male & $\chi^{2} / t$ & Female & Male & $\chi^{2 / t}$ \\
\hline$A g e^{\mathrm{a}}$ & $22.4(5.86)$ & $22.1(4.64)$ & $0.75^{* *}$ & $21.1(3.80)$ & $21.5(4.80)$ & -1.55 \\
\hline \multicolumn{7}{|l|}{ Race/Ethnicity } \\
\hline White & $1014(68.5 \%)$ & $296(73.1 \%)$ & $8.33^{*}$ & $600(70.8 \%)$ & $233(73.5 \%)$ & 2.72 \\
\hline Black & $83(5.6 \%)$ & $16(4.0 \%)$ & & $55(6.5 \%)$ & $13(4.1 \%)$ & \\
\hline Hispanic & $128(8.6 \%)$ & $20(4.9 \%)$ & & $39(4.6 \%)$ & $14(4.4 \%)$ & \\
\hline Asian & $120(8.1 \%)$ & $35(8.6 \%)$ & & $94(11.1 \%)$ & $37(11.7 \%)$ & \\
\hline Multi-Ethnic & $135(9.1 \%)$ & $38(9.4 \%)$ & & $59(7.0 \%)$ & $20(6.3 \%)$ & \\
\hline \multicolumn{7}{|l|}{ Sexual Orientation } \\
\hline Heterosexual & $1266(85.7 \%)$ & $364(88.1 \%)$ & 1.67 & $755(89.6 \%)$ & $288(90.3 \%)$ & 0.13 \\
\hline Non-Heterosexual & $212(14.3 \%)$ & $49(11.8 \%)$ & & $88(10.4 \%)$ & $31(9.7 \%)$ & \\
\hline \multicolumn{7}{|l|}{ Financial Security } \\
\hline Insecure & $927(62.9 \%)$ & $247(60.4 \%)$ & 0.85 & $444(53.1 \%)$ & $153(48.6 \%)$ & 1.89 \\
\hline Secure & $547(37.1 \%)$ & $162(39.6 \%)$ & & $392(46.9 \%)$ & $162(51.4 \%)$ & \\
\hline \multicolumn{7}{|l|}{ Religion } \\
\hline No & $465(31.5 \%)$ & $156(37.7 \%)$ & $6.64^{*}$ & $240(28.7 \%)$ & $120(37.9 \%)$ & $8.96^{* *}$ \\
\hline Yes & $1013(68.5 \%)$ & $252(61.8 \%)$ & & $596(71.3 \%)$ & $197(62.1 \%)$ & \\
\hline \multicolumn{7}{|l|}{ School Year } \\
\hline Freshman & $241(16.9 \%)$ & $34(8.7 \%)$ & $61.65^{* * *}$ & $145(17.9 \%)$ & $45(14.5 \%)$ & $12.41^{*}$ \\
\hline Sophomore & $285(20.0 \%)$ & $77(19.7 \%)$ & & $191(23.6 \%)$ & $64(20.6 \%)$ & \\
\hline Junior & $290(20.4 \%)$ & $100(25.6 \%)$ & & $184(22.7 \%)$ & $79(25.4 \%)$ & \\
\hline Senior & $382(26.9 \%)$ & $159(40.7 \%)$ & & $218(26.9 \%)$ & $108(34.7 \%)$ & \\
\hline Other & $224(15.8 \%)$ & $21(5.4 \%)$ & & $71(8.8 \%)$ & $15(4.8 \%)$ & \\
\hline \multicolumn{7}{|l|}{ IPV Training } \\
\hline No & $694(47.8 \%)$ & $212(52.5 \%)$ & 2.73 & $381(51.2 \%)$ & $159(53.9 \%)$ & 0.61 \\
\hline Yes & $757(52.2 \%)$ & $192(47.5 \%)$ & & $363(48.8 \%)$ & $136(46.1 \%)$ & \\
\hline \multicolumn{7}{|l|}{ Dormitory Resident } \\
\hline No & $1047(70.8 \%)$ & $309(75.7 \%)$ & 3.79 & $557(66.6 \%)$ & $215(68.0 \%)$ & 0.21 \\
\hline Yes & $431(29.0 \%)$ & $99(24.3 \%)$ & & $279(33.4 \%)$ & $101(32.0 \%)$ & \\
\hline
\end{tabular}


Table 1. Gender Differences in IPV Victimization, Demographics, and Physical and Behavioral Health $(n=3,070)$

\begin{tabular}{|c|c|c|c|c|c|c|}
\hline \multirow[b]{2}{*}{ Demographics } & \multicolumn{3}{|c|}{$\begin{array}{c}\text { IPV Victimization }(n=1,901) \\
\mathrm{n}(\%) / M(S D)^{\mathrm{a}}\end{array}$} & \multicolumn{3}{|c|}{$\begin{array}{c}\text { No IPV Victimization }(n=1,169) \\
\mathrm{n}(\%) / M(S D)^{\mathrm{a}}\end{array}$} \\
\hline & Female & Male & $\chi^{2 / t}$ & Female & Male & $\chi^{2} / t$ \\
\hline \multicolumn{7}{|l|}{ International Student } \\
\hline No & $1389(94.5 \%)$ & $388(95.6 \%)$ & 0.74 & $771(92.1 \%)$ & $292(93.0 \%)$ & 0.25 \\
\hline Yes & $81(5.5 \%)$ & $18(4.4 \%)$ & & $66(7.9 \%)$ & $22(7.0 \%)$ & \\
\hline Current NCS $S^{\mathrm{a}, \mathrm{b}}$ & $14.76(4.29)$ & $15.54(4.05)$ & -3.26 & $15.75(3.96)$ & $16.23(3.81)$ & -1.88 \\
\hline Childhood NCS $S^{\mathrm{a}, \mathrm{b}}$ & $16.59(4.55)$ & $17.16(4.15)$ & $-2.05^{*}$ & $17.60(3.81)$ & $17.54(4.10)$ & 0.19 \\
\hline \multicolumn{7}{|l|}{ Health } \\
\hline \multicolumn{7}{|l|}{ Physical Health } \\
\hline Not Good & $73(18.4 \%)$ & $52(12.6 \%)$ & 7.71 & $102(12.0 \%)$ & $39(12.3 \%)$ & 0.01 \\
\hline Good & $1213(81.6 \%)$ & $362(87.4 \%)$ & & $746(88.0 \%)$ & $279(87.7 \%)$ & \\
\hline \multicolumn{7}{|l|}{ Mental Health } \\
\hline Not Good & $369(24.8 \%)$ & $50(12.1 \%)$ & $30.64^{* * *}$ & $112(13.2 \%)$ & 29 (9.1\%) & 3.64 \\
\hline Good & $1117(75.2 \%)$ & $364(87.9 \%)$ & & $736(86.8 \%)$ & $289(90.9 \%)$ & \\
\hline \multicolumn{7}{|l|}{$B M I$} \\
\hline Under/ Normal & $896(66.2 \%)$ & $200(51.9 \%)$ & 26.22 & $553(73.8 \%)$ & $181(59.9 \%)$ & $19.74^{* * *}$ \\
\hline Overweight & $457(30.7 \%)$ & $185(48.1 \%)$ & & $196(26.2 \%)$ & $121(40.1 \%)$ & \\
\hline Depression $^{\mathrm{a}}$ & $18.01(12.06)$ & $14.52(11.06)$ & 5.40 & $12.85(10.12)$ & $11.57(9.23)$ & 1.89 \\
\hline \multicolumn{7}{|l|}{ Alcohol } \\
\hline Non-Drinker & $184(12.5 \%)$ & $43(10.4 \%)$ & 7.87 & $139(16.5 \%)$ & $50(15.8 \%)$ & $18.21^{* * *}$ \\
\hline Casual Drinker & $1153(78.1 \%)$ & $311(75.5 \%)$ & & $651(77.1 \%)$ & $221(69.9 \%)$ & \\
\hline Heavy Drinker & $140(9.5 \%)$ & $58(14.1 \%)$ & & $54(6.4 \%)$ & $45(14.2 \%)$ & \\
\hline \multicolumn{7}{|l|}{ Drug } \\
\hline Non-User & $941(63.4 \%)$ & $229(55.3 \%)$ & $26.71^{* * *}$ & $612(72.2 \%)$ & $199(62.4 \%)$ & $39.99^{* * *}$ \\
\hline Casual User & $448(30.2 \%)$ & $127(30.7 \%)$ & & $210(24.8 \%)$ & $80(25.1 \%)$ & \\
\hline Heavy User & $95(6.4 \%)$ & $58(14.0 \%)$ & & $26(3.1 \%)$ & $40(12.5 \%)$ & \\
\hline
\end{tabular}

$* p<.05, * * p<.01, * * * p<.001$ (significant results after adjusted Bonferroni correction)

${ }^{a}$ Frequency (Percent) for categorical variables (no denotation), Mean (Standard Deviation) for continuous variables

${ }^{\mathrm{b}}$ Neighborhood Child Safety Scale 
After IPV victimization, female students sought some type of help more than males ( $36.3 \%$ vs. $\left.17.1 \%, \chi^{2}(1)=46.25, p<0.001, V=.11\right)$. Of those who sought help, female students sought formal help more than males $\left(53.9 \%\right.$ vs. $29.3 \%, \chi^{2}(1)=12.53, p<0.001$, $V=.23$ ). Female and male students who experienced IPV victimization relied equally on informal help (88\%). Based on each post hoc comparison using the adjust Bonferroni correction, only formal help $(0.05 / 4=.0125)$ was significantly different by gender.

Table 2. Gender Differences in Types of IPV Victimization, IPV Consequences, and Helpseeking $(\mathrm{n}=1,901)$

\begin{tabular}{|c|c|c|c|c|}
\hline & & $\begin{array}{c}\text { Female } \\
n(\%)\end{array}$ & $\begin{array}{l}\text { Male } \\
n(\%)\end{array}$ & $\chi^{2}$ \\
\hline \multicolumn{5}{|l|}{ IPV Victimization } \\
\hline \multicolumn{5}{|l|}{ IPV Types } \\
\hline \multicolumn{2}{|l|}{ Physical } & $730(49.1 \%)$ & $164(39.6 \%)$ & $11.68^{* *}$ \\
\hline \multicolumn{2}{|l|}{ Psychological } & $1317(88.6 \%)$ & $368(88.9 \%)$ & 0.03 \\
\hline \multicolumn{2}{|l|}{ Sexual } & $701(47.3 \%)$ & $59(14.3 \%)$ & $147.17^{* * *}$ \\
\hline \multicolumn{2}{|l|}{ Technological } & $609(41.0 \%)$ & $91(22.0 \%)$ & $49.35^{* * *}$ \\
\hline \multicolumn{2}{|l|}{ Threats } & $463(31.1 \%)$ & $57(13.8 \%)$ & $48.86^{* * *}$ \\
\hline \multicolumn{5}{|l|}{ IPV Consequences } \\
\hline \multicolumn{5}{|l|}{ Physical Injuries } \\
\hline \multicolumn{2}{|l|}{ No } & $1106(83.9 \%)$ & $320(90.4 \%)$ & 9.34 \\
\hline \multicolumn{2}{|l|}{ Yes } & $212(16.1 \%)$ & $34(9.6 \%)$ & \\
\hline \multicolumn{5}{|l|}{ Feeling Afraid } \\
\hline \multicolumn{2}{|l|}{ Not at all } & $434(33.5 \%)$ & $263(75.8 \%)$ & 209.61 \\
\hline \multicolumn{2}{|l|}{ A little } & $550(42.5 \%)$ & $74(21.3 \%)$ & \\
\hline \multicolumn{2}{|c|}{ Very } & $310(24.0 \%)$ & $10(2.9 \%)$ & \\
\hline \multicolumn{5}{|c|}{ Daily Routine Problems } \\
\hline \multicolumn{2}{|c|}{ No } & $1082(82.7 \%)$ & $332(93.3 \%)$ & 24.34 \\
\hline \multicolumn{2}{|l|}{ Yes } & $226(17.3 \%)$ & $24(6.7 \%)$ & \\
\hline \multicolumn{5}{|l|}{ Help-Seeking } \\
\hline \multirow[t]{3}{*}{ Any Help } & & $829(63.7 \%)$ & $287(82.9 \%)$ & $46.25^{* * *}$ \\
\hline & Formal & $254(53.9 \%)$ & $17(29.3 \%)$ & \\
\hline & Informal & $411(87.3 \%)$ & $51(87.9 \%)$ & \\
\hline
\end{tabular}

When survivors sought formal help, just under half of female students and only a quarter of male students reported it as helpful $\left(\chi^{2}(1)=8.36, p<0.01, V=.17\right.$; Table 3$)$. For informal help, $71.6 \%$ of female students and $87.3 \%$ of male students found it helpful $\left(\chi^{2}(1)=6.20, p<0.05, V=.01\right)$. Each post hoc comparison examining the helpfulness of formal or informal help using the adjusted Bonferroni correction $(0.05 / 4=.0125)$ revealed that none of the pairwise comparisons were significant. 
Table 3. Gender Differences in Helpfulness of Help-Seeking

\begin{tabular}{l|l|c|c|c}
\hline $\begin{array}{c}\text { Type of Help- } \\
\text { Seeking }\end{array}$ & Helpful? & $\begin{array}{c}\text { Female } \\
n(\%)\end{array}$ & $\begin{array}{c}\text { Male } \\
n(\%)\end{array}$ & $\chi^{2}$ \\
\hline Formal Help & No & $251(54.1 \%)$ & $41(74.5 \%)$ & 8.36 \\
& Yes & $213(45.9 \%)$ & $14(25.5 \%)$ & \\
\hline Informal Help & No & $132(28.4 \%)$ & $7(12.7 \%)$ & 6.20 \\
& Yes & $332(71.6 \%)$ & $48(87.3 \%)$ & \\
\hline \multicolumn{2}{l}{ * no significant results after adjusted Bonferroni correction. } \\
\hline
\end{tabular}

The most reported reason for not seeking help by both men and women was that they thought it was a private or personal matter or they took care of it themselves (Table 4). Two reasons that showed the biggest gender differences were "Others would not think it was important enough" and "Did not want to get partner in trouble," which were more prevalent among female students than males $(21.1 \%$ vs. $12.2 \%$, and $15.8 \%$ vs. $9.8 \%$, respectively; $\left.\chi^{2}(1)=11.09, p<0.01, V=.25, \chi^{2}(1)=6.38, p<0.05, V=.02\right)$. There were some survivors, though only a few, who reported that they had difficulty because of their sexual orientation; this was more prevalent in male students than females $(3.5 \%$ vs. $1.4 \%$, $\left.\chi^{2}(1)=4.58, p<0.05, V=.03\right)$.

Table 4. Reasons for Not Seeking Help

\begin{tabular}{|c|c|c|c|}
\hline & $\begin{array}{c}\text { Female } \\
n(\%)\end{array}$ & $\begin{array}{l}\text { Male } \\
n(\%)\end{array}$ & $\chi^{2 \mathrm{a}}$ \\
\hline Private or personal matter or took care of it myself & $621(74.9 \%)$ & $204(71.1 \%)$ & 1.62 \\
\hline No insurance & $25(3.0 \%)$ & $8(2.8 \%)$ & 0.04 \\
\hline Did not want to get partner in trouble & $131(15.8 \%)$ & $28(9.8 \%)$ & $6.38^{*}$ \\
\hline Afraid of reprisal by partner & $77(9.3 \%)$ & $15(5.2 \%)$ & $4.65^{*}$ \\
\hline Fear of losing children or more trouble & $12(1.4 \%)$ & $2(0.7 \%)$ & 0.97 \\
\hline They would not think it was important enough & $175(21.1 \%)$ & $35(12.2 \%)$ & $11.09^{* *}$ \\
\hline They would be inefficient, ineffective & $120(14.5 \%)$ & $32(11.1 \%)$ & 2.00 \\
\hline They would be biased, would harass me, cause me trouble & $49(5.9 \%)$ & $13(4.5 \%)$ & 0.78 \\
\hline Did not want to or could not take time- Too inconvenient & $154(18.6 \%)$ & $50(17.4 \%)$ & 0.19 \\
\hline Hard to find or get help because of sexual orientation & $12(1.4 \%)$ & $10(3.5 \%)$ & $4.58^{*}$ \\
\hline
\end{tabular}

\section{Discussion}

The study results demonstrate gender differences in the type of IPV experienced, factors and health issues associated with IPV victimization, and help sources utilized. Our study findings suggest that all types of IPV victimization experiences other than psychological violence are disproportionately high among female students. Our findings are consistent with prior studies reporting no gender differences in the prevalence of psychological violence (Cho \& Huang, 2017; Dardis et al., 2017; Fass et al., 2008; Gover et al., 2008), and prominent gender differences in other types of IPV including sexual violence (Breiding et al., 2014). Our findings are in contrast to other studies reporting that the prevalence of physical violence is equally distributed across gender (Dardis et al., 2017; 
Gover et al., 2008) or that it is more prevalent among male students (Fass et al., 2008). Such inconsistencies may be due to differences in methodology across studies, such as sampling, measurement, and not factoring in self-defense (Allen et al., 2009).

Demographic factors associated with IPV victimization varied between the two genders. Female survivors were older, more often of Hispanic origin, and from less safe childhood neighborhoods than males. It would be premature to suggest that female students with such characteristics are victimized more than male students. Nonetheless, further research may prove worthwhile as such gender differences were not found among the students not victimized by IPV. Consistent with previous study results, female survivors reported poorer mental health than male survivors (Afifi et al., 2009; Kars \& O'Leary, 2010). This difference may have stemmed from their unique IPV victimization experiences, given that more female survivors than males were physically hurt and afraid when victimized, and had problems with daily routines afterwards. It may be that the more IPV one experiences, the more severe the consequences, both in the short- and long-terms. However, it is also possible that females in poor mental health in younger ages might have been more vulnerable to IPV than males, which may have resulted in more severe consequences following IPV victimization.

Not many survivors sought help; only $36.3 \%$ of females and $17.1 \%$ of males. Given the numerous health and social consequences of IPV, this low level of help-seeking is alarming. Study findings regarding reasons IPV survivors do not pursue assistance are particularly informative. Many survivors who did not seek any help reported that they considered IPV to be a private, personal matter, or not important, which aligns well with the existing literature (e.g., Douglas \& Hines, 2011; Edwards et al., 2011). It may be that many still believe IPV is a private matter and do not want to involve other parties, including providers of the services designed to help victims. The study findings revealed interesting gender differences in the reasons for not seeking help. Female survivors who did not seek help were much more likely to report that they did not want to get their partner in trouble and/or were afraid of reprisal by their partner than male survivors (15.8\% vs. 9.8\%, 9.3\% vs. 5.2\%, respectively), suggesting that female survivors perceive help-seeking as a potential danger to their relationship or their safety. In comparison to female survivors, some male IPV survivors did not seek help because of their sexual orientation, either they were unable to find services for themselves or feared they may not get the appropriate help they needed. While a lack of services for males and non-heterosexual survivors has been consistently reported (Carvalho et al., 2011; Douglas \& Hines, 2011; Tsui, 2014), it has rarely been identified that male non-heterosexual survivors may face more challenges than female counterparts. This study provides evidence that, in fact, there are additional challenges for non-heterosexual male IPV survivors in accessing services, which signifies the need for services targeting male non-heterosexual survivors.

When survivors in this study sought help, they used informal help much more often than formal help, which is consistent with the literature (Cho \& Huang, 2017; Coker et al., 2000; Edwards et al., 2011). There were differences in the perceived helpfulness between the two help types - many survivors reported that informal help was effective but only about half of survivors reported that formal help was useful. It is concerning that formal help, such as physicians and police, was not used by survivors frequently and, once used, 
was not found to be beneficial. There seemed to be gender differences in the type and the perceived effectiveness of the help that survivors received, although they were not statistically significant. First of all, female survivors were more likely than males to use formal help and found it useful. As discussed earlier, such gender differences may be related to a lack of services for males and limitations in the services that are available, in which male survivors, especially gay men, may be treated with less welcoming attitudes than females (Douglas \& Hines, 2011; Tsui, 2014). Another gender difference was that, although females used informal help as often as males, they found it less useful than males. This may be due to the "negative" help female survivors often receive from informal help sources, such as not taking IPV situations seriously and/or pressing them to take certain actions against their preferences (Edwards et al., 2011; Sylaska \& Edwards, 2014). Future research is needed to confirm these relationships that were suggested but not found to be significant statistically.

The study findings should be interpreted in the context of a few methodological limitations. This study used cross-sectional survey data, and was, therefore, not able to substantiate potentially causal relationships. Although recruited from diverse areas of the U.S., the sample was not nationally representative. Some gender differences and other relationships that were found to be significant might have been affected by the sample limitations. While this study inquired about sexual orientation of the respondents, those identifying as Others were excluded from the analysis. They may include trans-identified, non-binary, or gender fluid-identified students, who may often experience the highest rates of violence and be excluded from help-seeking for many reasons (Schwab-Reese et al., 2018). Bivariate analyses were primarily used to identify significant associates of IPV, help-seeking, and gender differences. Multivariate analyses of variables found to be significant in this study, including the differential effects of the associated factors and potential interactions among them, are recommended for future research.

\section{Conclusion}

Gender differences were apparent in IPV experiences, helping-seeking behaviors, and the perceived helpfulness of formal and informal resources among college students in the current study. The study findings suggest important implications for intervention strategies to prevent and intervene in IPV among young adults, particularly on college campuses. Furthermore, the findings yield implications for crucial roles social workers could play to empower college IPV survivors to seek help.

First, the disproportionate concentration of IPV victimization experiences among females suggests a need to engage both males and females in campus interventions to educate them about power dynamics in romantic relationships. Since female students suffered from more severe IPV consequences than males, it is important that service providers, such as community domestic violence advocates and social workers, on-campus counselors, and student health center professionals, consider the severe negative consequences of IPV among females when planning prevention and intervention programs. At the same time, a significant number of male college students experienced IPV, implying that campus service providers need to exert greater effort in making the services available for male student survivors. 
Only a small portion of the survivors of IPV in the current study sought any type of help following their IPV experiences. For both female and male survivors, the most-often reported reasons for not seeking help were that they considered IPV to be a private/personal matter, believed that helpers would not take IPV seriously, and felt that seeking help was inconvenient. Such perceptions on the survivors' part suggest that campus communities must take steps to eliminate the stigma facing survivors of IPV. These remedies are crucial for empowering both genders to reach out for help, but it might be even more important for male survivors of IPV. Male survivors may feel more stigmatized or embarrassed in the context of official settings, where helping professionals may minimize their IPV experiences and their detrimental impact (Tsui et al., 2010).

Making services and resources available by eliminating the stigma toward IPV can also encourage male survivors in same-sex relationships to seek help as they may currently experience more severe stigmatization due to their sexual orientation, in addition to being male survivors. Social workers should also invest efforts to inclusively and sensitively serve this population. For example, it is important that they are conscious about their known or unknown bias and potentially discriminatory attitudes toward non-heterosexual IPV survivors (Ard \& Makadon, 2011; Calton et al., 2016). For social workers to engage in such reflective practice, they first need to understand the struggles and challenges nonheterosexual IPV survivors might experience. Social work education and social service agencies serving IPV survivors should provide relevant trainings for social workers to effectively reach out to and assist this population (Calton et al., 2016). In college contexts, such efforts to enhance sensitivity toward non-heterosexual IPV survivors should also be made by not only helping professionals (e.g., counselors and health service providers), but also academic instructors and staff so that the survivors feel more comfortable in approaching informal and formal sources of help. Furthermore, future research needs to comprehensively explore gender, beyond the male/female binary, which will produce a better understanding of non-heterosexual college students' help-seeking behaviors. In turn, such knowledge could yield implications for tailored social work practice and policy to better assist non-heterosexual college students suffering from IPV.

Finally, both female and male survivors sought informal help more often than formal help after experiencing IPV victimization. Social workers can be at the forefront of developing and implementing educational and communicative programs in collaboration with colleges, targeting such sources of informal help as family and friends so that survivors can receive and/or be guided to the appropriate help. Furthermore, through these programs, social workers could educate community members, who might be the informal sources of help to survivors, about "how to respond to the disclosure of IPV" (Edwards et al., 2011, p. 515). Our findings revealed gender differences in the perceived helpfulness of the assistance sought. For victim services to be effective, future research needs to examine what aspects and processes of help-seeking are perceived by the survivors as being helpful, or not, and the role gender plays in those relationships.

\section{References}

Afifi, T. O., MacMillan, H., Cox, B. J., Asmundson, G. J. G., Stein, M. B., \& Sareen, J. (2009). Mental health correlates of intimate partner violence in marital relationships 
in a nationally representative sample of males and females. Journal of Interpersonal Violence, 24(8), 1398-1417. https://doi.org/10.1177/0886260508322192

Alegria, M., Vila, D., Woo, M., Canino, G., Takeuchi, D., Vera, M., \& Shrout, P. (2004). Cultural relevance and equivalence in the NLAAS instrument: Integrating etic and emic in the development of cross-cultural measures for a psychiatric epidemiology and services study of Latinos. International Journal of Methods in Psychiatric Research, 13, 270-288. https://doi.org/10.1002/mpr.181

Allen, C. T., Swan, S. C., \& Raghavan, C. (2009). Gender symmetry, sexism, and intimate partner violence. Journal of Interpersonal Violence, 24(11), 1816-1834. https://doi.org/10.1177/0886260508325496

Amar, A. F., \& Gennaro, S. (2005). Dating violence in college women: Associated physical injury, healthcare usage, and mental health symptoms. Nursing Research, 54(4), 235-242. https://doi.org/10.1097/00006199-200507000-00005

Ansara, D. L., \& Hindin, M. J. (2010). Formal and informal help-seeking associated with women's and men's experiences of intimate partner violence in Canada. Social Science \& Medicine, 70(7), 1011-1018. https://doi.org/10.1016/j.socscimed.2009.12.009

Ard, K. L., \& Makadon, H. (2011). Addressing intimate partner violence in Lesbian, Gay, Bisexual, and Transgender patients. Journal of General Internal Medicine, 26, 930933. https://doi.org/10.1007/s11606-011-1697-6

Banyard, V. L., \& Cross, C. (2008). Consequences of teen dating violence: Understanding intervening variables in ecological context. Violence Against Women, 14(9), 998-1013. https://doi.org/10.1177/1077801208322058

Bennett, L., Riger, S., Schewe, P., Howard, A., \& Wasco, S. (2004). Effectiveness of hotline advocacy, counseling, and shelter services for victims of domestic violence: A statewide evaluation. Journal of Interpersonal Violence, 19(7), 815-829. https://doi.org/10.1177/0886260504265687

Breiding, M. J., Basile, K. C., Smith, S. G., Black, M. C., \& Mahendra, R. (2015). Intimate partner violence surveillance: Uniform definitions and recommended data elements. Atlanta, GA: National Center for Injury Prevention and Control, Centers for Disease Control and Prevention. https://www.cdc.gov/violenceprevention/pdf/ipv/intimatepartnerviolence.pdf

Breiding, M. J., Chen, J., \& Black, M. C. (2014). Intimate partner violence in the United States-2010. National Center for Injury Prevention and Control, Centers for Disease Control and Prevention. https://www.cdc.gov/violenceprevention/pdf/cdc_nisvs_ipv_report_2013_v17_single a.pdf

Caldwell, J. E., Swan, S. C., \& Woodbrown, V. D. (2012). Gender differences in intimate partner violence outcomes. Psychology of Violence, 2(1), 42-57. https://doi.org/10.1037/a0026296 
Calton, J. M., Cattaneo, L. B., \& Gebhard, K. T. (2016). Barriers to help seeking for Lesbian, Gay, Bisexual, Transgender, and Queer survivors of intimate partner violence. Trauma, Violence, \& Abuse, 17, 585-600. https://doi.org/10.1177/1524838015585318

Campbell, E. (2016). Racializing intimate partner violence among Black, Native American, Asian American and Latina women. International Journal of Progressive Education, 12(2), 64-77.

Campbell, R. (2006). Rape survivors' experiences with legal and medical systems: Do rape victim advocates make a difference? Violence Against Women, 12, 30-45. https://doi.org/10.1177/1077801205277539

Carvalho, A. F., Lewis, R. J., Derlega, V. J., Winstead, B. A., \& Viggiano, C. (2011). Internalized sexual minority stressors and same-sex intimate partner violence. Journal of Family Violence, 26(7), 501-509. https://doi.org/10.1037/e 701962011-001

Centers for Disease Control and Prevention. (2014). Calculating BMI using the English system.https:/www.cdc.gov/nccdphp/dnpao/growthcharts/training/bmiage/page5 2.h $\underline{\mathrm{tml}}$

Cho, H., \& Huang, L. (2017). Aspects of help seeking among collegiate victims of dating violence. Journal of Family Violence, 32(4), 409-417. https://doi.org/10.1007/s10896-016-9813-3

Cho, H., Shamrova, D., Han, J., \& Levchenko, P. (in press). Patterns of intimate partner violence victimization and survivors' help-seeking. Journal of Interpersonal Violence.

Coker, A. L., Davis, K. E., Arias, I., Desai, S., Sanderson, M., Brandt, H. M., \& Smith, P. H. (2002). Physical and mental health effects of intimate partner violence for men and women. American Journal of Preventive Medicine, 23(4), 260-268. https://doi.org/10.1016/s0749-3797(02)00514-7

Coker, A. L., Derrick, C., Lumpkin, J. L., Aldrich, T. E., \& Oldendick, R. (2000). Helpseeking for intimate partner violence and forced sex in South Carolina. American Journal of Preventive Medicine, 19(4), 316-320. https://doi.org/10.1016/s0749$\underline{3797(00) 00239-7}$

Daley, E. M., \& Noland, V. J. (2001). Intimate partner violence in college students: A cross-cultural comparison. International Electronic Journal of Health Education, 4, $35-40$.

Dardis, C. M., Edwards, K. M., Kelley, E. L., \& Gidycz, C. A. (2017). Perceptions of dating violence and associated correlates: A study of college young adults. Journal of Interpersonal Violence, 32(21), 3245-3271. https://doi.org/10.1177/0886260515597439

Domenech del Rio, I., \& Sirvent Garcia del Valle, E. (2017). The consequences of intimate partner violence on health: A further disaggregation of psychological 
violence: Evidence from Spain. Violence Against Women, 23(14), 1771-1789. https://doi.org/10.1177/1077801216671220

Douglas, E. M., \& Hines, D. A. (2011). The helpseeking experiences of men who sustain intimate partner violence: An overlooked population and implications for practice. Journal of Family Violence, 26, 473-485. https://doi.org/10.1007/s10896-011-9382-4

Duke, A., \& Davidson, M. M. (2009). Same-sex intimate partner violence: Lesbian, Gay, and Bisexual affirmative outreach and advocacy. Journal of Aggression, Maltreatment \& Trauma, 18, 795-816. https://doi.org/10.1080/10926770903291787

Edwards, K. M., Dardis, C. M., \& Gidycz, C. A. (2011). Women's disclosure of dating violence: A mixed methodological study. Feminism \& Psychology, 22(4), 507-517. https://doi.org/10.1177/0959353511422280

Ehrensaft, M. K., Moffitt, T. E., \& Caspi, A. (2006). Is domestic violence followed by an increased risk of psychiatric disorders among women but not among men? A longitudinal cohort study. American Journal of Psychiatry, 163(5), 885-892. https://doi.org/10.1176/ajp.2006.163.5.885

Fass, D. F., Benson, R. I., \& Leggett, D. G., (2008). Assessing prevalence and awareness of violent behaviors in the intimate partner relationships of college students using Internet Sampling. Journal of College Student Psychotherapy, 22(4), 66-75. https://doi.org/10.1080/87568220801952248

Fergusson, D. M., Horwood, L. J., \& Ridder, E. M. (2005). Partner violence and mental health outcomes in a New Zealand birth cohort. Journal of Marriage and Family, 67(5), 1103-1119. https://doi.org/10.1111/j.1741-3737.2005.00202.x

Fortin, I., Guay, S., Lavoie, V., Boisvert, J.-M., \& Beaudry, M. (2012). Intimate partner violence and psychological distress among young couples: Analysis of the moderating effect of social support. Journal of Family Violence, 27, 63-73. https://doi.org/10.1007/s10896-011-9402-4

Garcia-Moreno, C., Jansen, H. A., Ellsberg, M., Heise, L., \& Watts, C. H. (2006). Prevalence of intimate partner violence: Findings from the WHO multi-country study on women's health and domestic violence. The Lancet, 368(9543), 1260-1269. https://doi.org/10.1016/s0140-6736(06)69523-8

Gover, A. G., Kaukinen, C., \& Fox, K. A. (2008). The relationship between violence in the family of origin and dating violence among college students. Journal of Interpersonal Violence, 23(12), 1667-1693. https://doi.org/10.1177/0886260508314330

Greenman, S. J., \& Matsuda, M. (2016). From early dating violence to adult intimate partner violence: Continuity and sources of resilience in adulthood. Criminal Behaviour and Mental Health, 26(4), 293-303. https://doi.org/10.1002/cbm.2012

Guth, A. A., \& Pachter, H. L. (2000). Domestic violence and the trauma surgeon. American Journal of Surgery, 179(2), 134-140. https://doi.org/10.1016/S0002$\underline{9610(00) 00245-2}$ 
Hamberger, L. K., \& Larsen, S. E. (2015). Men's and women's experience of intimate partner violence: A review of ten years of comparative studies in clinical samples; Part I. Journal of Family Violence, 30(6), 699-717. https://doi.org/10.1007/s10896-015-9732-8

Hamby, S. (2013). The partner victimization scale. Life Paths Research Program. https://www.lifepathsresearch.org/wp-content/uploads/Partner-VictimizationScale1.pdf

Hamby, S. (2016). Self-report measures that do not produce gender parity in intimate partner violence: A multi-study investigation. Psychology of Violence, 6(2), 323-335. https://doi.org/10.1037/a0038207

Hancock, K., Keast, H., \& Ellis, W. (2017). The impact of cyber dating abuse on selfesteem: The mediating role of emotional distress. Cyberpsychology: Journal of Psychosocial Research on Cyberspace, 11(2), Article 2. https://doi.org/10.5817/cp2017-2-2

Harned, M. S., \& Vict, V. (2001). Abused women or abused men? An examination of the context and outcomes of dating violence. Violence and Victims, 16(3), 269-285. https://doi.org/10.1891/0886-6708.16.3.269

Jina, R., \& Thomas, L. S. (2013). Health consequences of sexual violence against women. Best Practices \& Research Clinical Obstetrics and Gynaecology, 27, 15-26. https://doi.org/10.1016/j.bpobgyn.2012.08.012

Kars, H. L., \& O'Leary, K. D. (2010). Gender symmetry or asymmetry in intimate partner victimization? Not an either/or answer. Partner Abuse, 1(2), 152-168. http://dx.doi.org/10.1891/1946-6560.1.2.152

Kilpatrick, D. G., Saunders, B. E., \& Smith, D. W. (2000). Youth victimization: Prevalence and implications. U.S. Department of Justice, Office of Justice Programs, National Institute of Justice. https://www.ncjrs.gov/pdffiles1/nij/194972.pdf

Laing, L. (2017). Secondary victimization: Domestic violence survivors navigating the family law system. Violence Against Women, 23(11), 1314-1335. https://doi.org/10.1177/1077801216659942

Langton, L., Berzofsky, M., Krebs, C. P., \& Smiley-McDonald, H. (2012). Victimizations not reported to the police 2006-2010. US Department of Justice, Office of Justice Programs, Bureau of Justice Statistics. https://doi.org/10.1037/e378272004-001

Lutwak, N. (2018). The psychology of health and illness: The mental health and physiological effects of intimate partner violence on women. Journal of Psychology, 152(6), 373-387. https://doi.org/10.1080/00223980.2018.1447435

MacDonald, P. L., \& Gardner, R. C. (2000). Type I error rate comparisons of post hoc procedures for I j Chi-Square tables. Educational and Psychological Measurement, 60(5), 735-754. https://doi.org/10.1177/00131640021970871 
Neville, H., Heppner, M., Oh, E., Spainerman, L., \& Clark, M. (2004). General and culturally specific factors influencing Black and White rape survivor's self-esteem. Psychology of Women Quarterly, 28, 83-94. https://doi.org/10.1111/j.14716402.2004.00125.x

Porcerelli, J. H., Cogan, R., West, P. P., Rose, E. A., Lambrecht, D., Wilson, K. E., ... Karana, D. (2003). Violent victimization of women and men: Physical and psychiatric symptoms. Journal of the American Board of Family Practice, 16(1), 3239. https://doi.org/10.3122/jabfm.16.1.32

Radloff, L. S. (1977). The CES-D scale: A self-report depression scale for research in the general population. Applied Psychological Measurements, 1, 385-401. https://doi.org/10.1177/014662167700100306

Rich, K., \& Seffrin, P. (2013). Police officers' collaboration with rape victim advocates: Barriers and facilitators. Violence and Victims, 28(4), 681-696. doi:10.1891/08866708. https://doi.org/10.1891/0886-6708.vv-d-12-00044

Romito, P., \& Grassi, M. (2007). Does violence affect one gender more than the other? The mental health impact of violence among male and female university students. Social Science \& Medicine, 65(6), 1222-1234. https://doi.org/10.1016/j.socscimed.2007.05.017

Saewyc, E. M., Brown, D., Plane, M., Mundt, M. P., Zakletskaia, L., Wiegel, J., \& Fleming, M. F. (2009). Gender differences in violence exposure among university students attending campus health clinics in the United States and Canada. Journal of Adolescent Health, 45, 587-594. https://doi.org/10.1016/j.jadohealth.2009.03.024

Santaularia, J., Johnson, M., Hart, L., Haskett, L., Welsh, E., \& Faseru, B. (2014). Relationships between sexual violence and chronic disease: A cross-sectional study. BMC Public Health, 14, 1286-1299. https://doi.org/10.1186/1471-2458-14-1286

Scherer, H. L., Snyder, J. A., \& Fisher, B. S. (2016). Intimate partner victimization among college students with and without disabilities: Prevalence of and relationship to emotional well-being. Journal of Interpersonal Violence, 31(1), 49-80. https://doi.org/10.1177/0886260514555126

Schwab-Reese, L. M., Currie, D., Mishra, A. A., \& Peek-Asa, C. (2018). A comparison of violence victimization and polyvictimization among sexual minority and heterosexual adolescents and young adults. Journal of Interpersonal Violence. https://doi.org/10.1177/0886260518808853

Smith, P. H., White, J. W., \& Holland, L. J. (2003). A longitudinal perspective on dating violence among adolescent and college-age women. American Journal of Public Health, 93(7), 1104-1109. https://doi.org/10.2105/ajph.93.7.1104

Smith, S. G., Basile, K. C., Gilbert, L. K., Merrick, M. T., Patel, N., Walling, M., \& Jain, A. (2017). National Intimate Partner and Sexual Violence Survey (NISVS): 2010-2012 state report. National Center for Injury Prevention and Control, Centers for Disease Control and Prevention. https://doi.org/10.1037/e308842004-001 
Southworth, C., Finn, J., Dawson, S., Fraser, C., \& Tucker, S. (2007). Intimate partner violence, technology, and stalking. Violence Against Women, 13(8), 842-856. https://doi.org/10.1177/1077801207302045

Straus, M. A., \& Gozjolko, K. L. (2014). "Intimate Terrorism" and gender differences in injury of dating partners by male and female university students. Journal of Family Violence, 29(1), 51-65. https://doi.org/10.1007/s10896-013-9560-7

Sylaska, K. M., \& Edwards, K. M. (2014). Disclosure of intimate partner violence to informal social support network members: A review of the literature. Trauma, Violence, \& Abuse, 15(1), 3-21. https://doi.org/10.1177/1524838013496335

Tsui, V. (2014). Male victims of intimate partner abuse: Use and helpfulness of services. Social Work, 59(2), 121-130. https://doi.org/10.1093/sw/swu007

Tsui, V., Cheung, M., \& Leung, P. (2010). Help-seeking among male victims of partner abuse: Men's hard times. Journal of Community Psychology, 38(6), 769-780. https://doi.org/10.1002/jcop.20394

Velopulos, C., Carmichael, H., Zakrison, T., \& Crandall, M. (2019). Comparison of male and female victims of intimate partner homicide and bidirectionality: An analysis of the National Violent Death Reporting System. Journal of Trauma and Acute Care Surgery, 87(2), 331-336. https://doi.org/10.1097/ta.0000000000002276

Wasserman, C. (2003). Dating violence on campus: A fact of life. National Center for Victims of Crime. https://www.ocrsm.umd.edu/files/Dating-Violence-on-Campus-AFact-of-Life-2003.pdf

Watkins, L. E., Maldonado, R. C., \& DiLillo, D. (2018). The cyber aggression in relationships scale: A new multidimensional measure of technology-based intimate partner aggression. Assessment, 25(5), 608-626. https://doi.org/10.1177/1073191116665696

Woodin, E. M., Sotskova, A., \& O’Leary, K. D. (2013). Intimate partner violence assessment in an historical context: Divergent approaches and opportunities for progress. Sex Roles, 69(3-4), 120-130. https://doi.org/10.1007/s11199-013-0294-z

Author note: Address correspondence to Dr. Jisuk Seon, Brown School, Washington University in St. Louis. Campus Box 1196, One Brookings Drive, St. Louis, MO 63130. E-mail: jseon@,wustl.edu 